Research Article

\title{
Safety Factor of Unsaturated Soil Slopes considering the Intermediate Principal Stress Effect and Different Profiles of Matric Suction
}

\author{
Zhaoxin Li $\left(\mathbb{1},{ }^{1}\right.$ Changguang Zhang $\left(\mathbb{\infty},{ }^{2}\right.$ Jingyuan Zhao $(1),{ }^{1}$ and Qing Yan $\left(\oplus^{2}\right.$ \\ ${ }^{1}$ School of Architecture, Chang'an University, Xi'an 710061, China \\ ${ }^{2}$ School of Civil Engineering, Chang'an University, Xi'an 710061, China \\ Correspondence should be addressed to Changguang Zhang; zcg1016@163.com and Jingyuan Zhao; zjyqtt@163.com
}

Received 27 November 2020; Revised 26 January 2021; Accepted 23 March 2021; Published 5 April 2021

Academic Editor: Rossana Dimitri

Copyright (c) 2021 Zhaoxin Li et al. This is an open access article distributed under the Creative Commons Attribution License, which permits unrestricted use, distribution, and reproduction in any medium, provided the original work is properly cited.

Profiles of matric suction are critical for assessing the stability of unsaturated soil slopes, and the strength of unsaturated soils is affected by the intermediate principal stress. This study presents a theoretical formulation of safety factor for infinite unsaturated soil slopes under four different profiles of matric suction using the limit equilibrium method. The unified shear strength equation under plane strain conditions is adopted to capture the effect of intermediate principal stress on the strength of unsaturated soils. The proposed formulation of safety factor is found to have good comparability and broad applicability. The validity of the proposed formulation is demonstrated by comparing its predictions with the results of the extended shear strength method and the finite element method available in the literature. Parametric studies show that the effect of intermediate principal stress on the stability of unsaturated soil slopes is significant; the difference of safety factor among four suction profiles is pronounced, and the safety factor is highest for a linear suction profile. In addition, the safety factor changes with the infiltration depth in two stages, decreases with the slope angle, and increases with effective strength parameters. The results of this study are capable of providing beneficial guidance for optimization designs and disaster preventions of unsaturated soil slopes.

\section{Introduction}

The safety factor of an infinite slope is commonly defined as the ratio of shear strength of the soil to the shear stress developed along a sliding surface, and it is a critical indicator for evaluating slope stability situations. The slope is in a stable state if the safety factor is greater than one, whereas the slope is unstable when the safety factor is less than one. Rainfall infiltration reduces matric suction and thereby deteriorates unsaturated soil strength, and the safety factor of unsaturated soil slopes is subsequently decreased, which is one of the main causes to trigger slope instability in tropical and subtropical regions $[1,2]$. Numerous investigations have been undertaken to address the failure mechanism and stability of rainfall-induced landslides using field monitoring, model tests, and numerical modeling [3-12].
Alternatively, the limit equilibrium method as a theoretical analysis is also widely adopted to deal with the slope stability of unsaturated soils [13-19], and the obtained formulation preferred for its simplicity is readily to be used by practical engineers.

For theoretical analyses on the slope stability not incorporating the hydromechanical behavior of unsaturated soils, matric suction is utilized gradually from the initial assumption as a constant to a linear profile with depth under the hydrostatic condition. Comparing with the uniform suction profile, the linear suction profile is more consistent with actual situations of unsaturated soils. Matric suction of unsaturated soils, however, cannot be always maintaining a linear profile relative to complicated external environments such as rainfall, infiltration, and evaporation. Therefore, the diversity and variation of various suction profiles should be 
allowed for to better assess the slope stability from the point of view of the unsaturated soil mechanics. Rahardjo et al. [13] derived the safety factor equation of infinite unsaturated soil slopes for the linear suction profile under a hydrostatic condition and three different suction profiles under a nonhydrostatic condition. Lu and Godt [14] developed an analytical approach to analyze slope stability using the concept of the suction stress. Travis et al. [15] presented a closed-form solution of safety factor for an infinite slope with the consideration of surface flux conditions. Zhang et al. [16] discussed the safety factor of an infinite unsaturated soil slope with several semiempirical nonlinear shear strength equations under a linear suction profile.

The preceding studies were conducted on the basis of the Mohr-Coulomb (MC) failure criterion within the framework of the two independent stress state variables theory, the effective stress theory, or the suction stress theory. It is well recognized that the MC failure criterion is independent of the intermediate principal stress, and it cannot account for the effect of intermediate principal stress on unsaturated soil strength. There have been increasing experimental evidence that the intermediate principal stress enhances the strength of unsaturated soils substantially [20-24], and unsaturated soil strength is conservatively estimated when the intermediate principal stress effect is not included. As a result, the slope stability of unsaturated soils is underestimated along with a smaller safety factor based on the MC failure criterion attributed to not achieving strength contributions from the intermediate principal stress effect. Zhang et al. $[25,26]$ presented a unified shear strength equation of unsaturated soils under plane strain conditions by combining the unified strength theory [27] with the theory of two independent stress state variables [28] in conjunction with the extended analogy methodology. Integrated effects of matric suction and intermediate principal stress on the strength of unsaturated soils are reasonably considered by the unified shear strength equation. Meanwhile, the unified shear strength equation has been successfully applied to typical geotechnical engineering problems [29-32], such as the Earth pressure of retaining walls, the bearing capacity of strip foundations, and the slope stability with the upper bound theorem of limit analysis.

The objective of this study is to present theoretical formulations of safety factor for an infinite unsaturated soil slope under four different profiles of matric suction based on the limit equilibrium method. The effect of intermediate principal stress on the strength of unsaturated soils is described by the unified shear strength equation. Furthermore, the proposed formulation is conducted for a comparability analysis, and it is verified against two published results of unsaturated soil slope stability. Finally, a parametric study is performed to explore the effect of typical parameters (e.g., the intermediate principal stress, the infiltration depth, the slope angle, and effective strength parameters) involved in the proposed formulation on the stability of unsaturated soil slopes under four suction profiles.

\section{Shear Strength of Unsaturated Soils under Plane Strain Conditions}

The unified equation of shear strength $\left(\tau_{f}\right)$ for unsaturated soils under plane strain conditions $[25,26]$ is written as

$$
\begin{aligned}
\tau_{f} & =c_{t}^{\prime}+\left(\sigma-u_{a}\right) \tan \varphi_{t}^{\prime}+\left(u_{a}-u_{w}\right) \tan \varphi_{t}^{b} \\
& =c_{t t}+\left(\sigma-u_{a}\right) \tan \varphi_{t}^{\prime}, \\
\sin \varphi_{t}^{\prime} & =\frac{2(1+b) \sin \varphi^{\prime}}{2+b\left(1+\sin \varphi^{\prime}\right)}, \\
c_{t}^{\prime} & =\frac{2(1+b) c^{\prime} \cos \varphi^{\prime}}{2+b\left(1+\sin \varphi^{\prime}\right)} \frac{1}{\cos \varphi_{t}^{\prime}}, \\
\sin \varphi_{t}^{b} & =\frac{2(1+b) \sin \varphi^{b}}{2+b\left(1+\sin \varphi^{b}\right)}, \\
c_{t t} & =c_{t}^{\prime}+\left(u_{a}-u_{w}\right) \tan \varphi_{t}^{b},
\end{aligned}
$$

where $c^{\prime}=$ effective cohesion, $c_{t}^{\prime}=$ unified effective cohesion, $c_{t t}=$ unified total cohesion, $\varphi^{\prime}=$ effective internal friction angle, $\varphi_{t}^{\prime}=$ unified effective internal friction angle, $\varphi^{b}=$ friction angle relative to matric suction, $\varphi_{t}^{b}=$ unified friction angle with matric suction, $u_{a}=$ pore-air pressure, $u_{w}=$ pore-water pressure, $u_{a}-u_{w}=$ matric suction, $\sigma=$ total normal stress, $\sigma-u_{a}=$ net normal stress, $b=$ unified strength theory parameter, and $0 \leq b \leq 1$. The parameter $b$ represents the effect of intermediate principal stress on the strength of unsaturated soils, and it can be calculated by the values of basic mechanical properties (e.g., uniaxial compressive strength, uniaxial tensile strength, and pure shear strength) or comparing the limit loci of equation (1) with true triaxial tests of unsaturated soils on a deviatoric plane. In addition, the friction angle $\varphi^{b}$ is simply taken as a constant not larger than the effective internal friction angle $\varphi^{\prime}$, and its variation with respect to matric suction can be well addressed by a hyperbolic function similar to that of Zhang et al. [29] and Yan et al. [30].

Equation (1) was initially presented using the extended analogy methodology $[25,26]$ with the variation of parameter $b$ from 0 to 1 corresponding to different cohesion intercepts and different inclined angles, as shown in Figure 1. In fact, equation (1) can also be derived from the unified failure criterion of unsaturated soils [22] under the plane strain condition (i.e., the intermediate principal strain $\varepsilon_{2}=0$ ). Additionally, equation (1) has an identical form as the theory of two independent stress state variables [28].

Equation (1) accounts for the effect of intermediate principal stress on unsaturated soil strength through parameter $b$ conforming to different failure criteria. For instance, when $b=0$, equation (1) is degenerated into the conventional shear strength equation in terms of two independent stress state variables for unsaturated soils [28] based on the MC failure criterion not including the intermediate principal stress. When $b=1$, equation (1) reduces to 


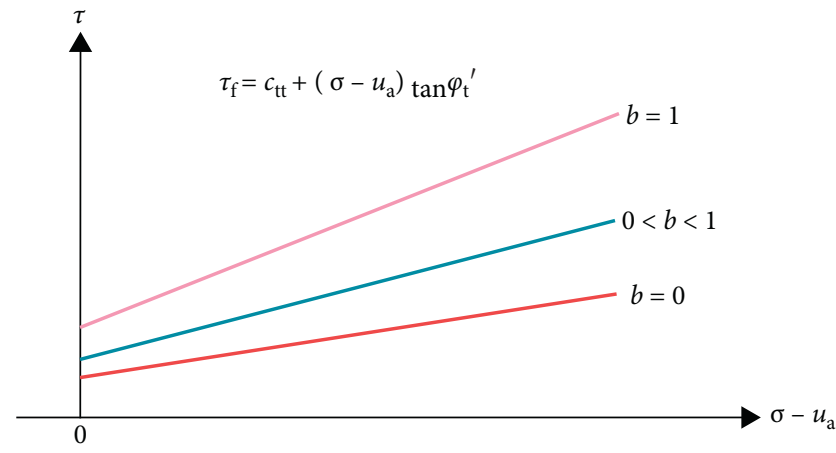

FIGURE 1: Shear strength of unsaturated soils under a plain strain condition.

the shear strength equation of unsaturated soils obeying the twin-shear stress failure criterion, where the intermediate principal stress effect is the largest. Furthermore, $b$ is in the range of 0 to 1 (i.e., $0<b<1$ ), and equation (1) yields a series of new shear strength equations for unsaturated soils. Therefore, slope stability of unsaturated soils can be conducted reasonably by equation (1) with due consideration of the intermediate principal stress effect and different failure criteria under a plane strain condition.

\section{Safety Factor of Unsaturated Soil Slopes}

3.1. Profiles of Matric Suction. A transient saturated area occurs during rainfalls leading to the decrease of shear strength for shallow unsaturated soils. Consequently, the homogeneous infinite unsaturated soil slope generally appears a shallow sliding failure plane parallel to the slope surface above the water table in Figure $2[1,2,33,34]$ subject to vertical steady unsaturated infiltration conditions. This study will discuss two pore-water pressure conditions: hydrostatic and nonhydrostatic conditions, without incorporating actually sophisticated rainfall seepage processes. The profile of matric suction is linear under a hydrostatic condition, and matric suction decreases linearly with depth to zero at the water table $H$. There are three cases of suction profiles under a nonhydrostatic condition in Figure 2 [13], denoted as case I, case II, and case III.

(1) The suction profile of case I frequently takes place for fine-grained unsaturated soils. Matric suction is zero at the ground surface, increases linearly with depth to the infiltration depth $Z$, and then decreases linearly to zero at the water table.

(2) The suction profile of case II generally exists for coarse-grained unsaturated soils. Matric suction is zero above the infiltration depth $Z$, but increases suddenly at the infiltration depth $Z$, and then decreases linearly with depth to zero at the water table.

(3) The suction profile of case III is particular for layered unsaturated soils. A positive pore-water pressure is built up above the infiltration depth $Z$, and matric suction in the depth of $(H-Z)$ becomes the linear suction profile under a hydrostatic condition.

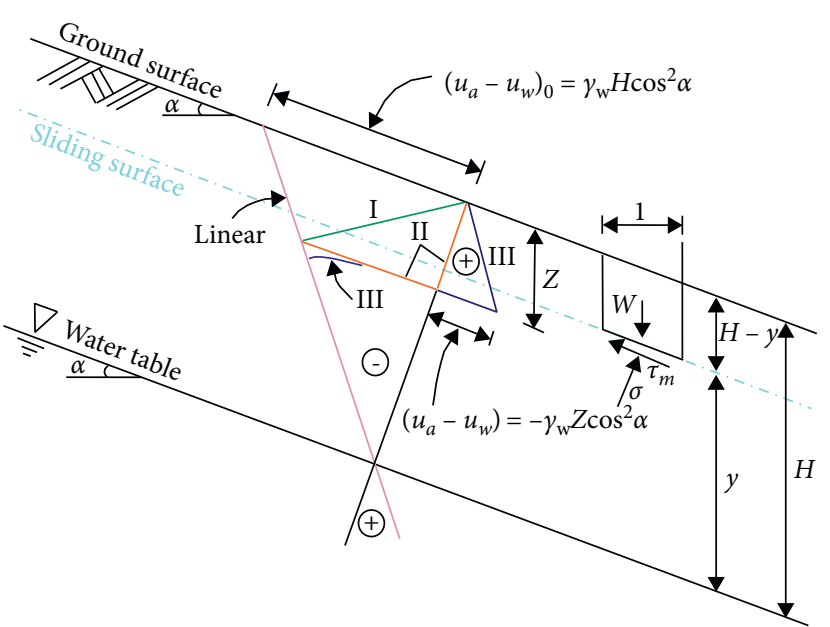

Figure 2: Failure mode of an infinite unsaturated soil slope and four profiles of matric suction.

3.2. Formulation of Safety Factor. It is assumed that the water table is parallel to the slope surface, and the unit weight $\gamma$ of unsaturated soils is a constant. Because of the pore air in unsaturated soils connecting to the atmosphere, the pore-air pressure $u_{a}$ equals to zero. As shown in Figure $2, W$ is the unit self-weight of unsaturated soils above the sliding surface, while $\sigma$ is the total normal stress that is a normal component of the soil self-weight perpendicular to the sliding surface, and $\tau_{m}$ is the shear stress that is a tangential component of the soil self-weight along the sliding surface. The safety factor of an infinite slope is the ratio of shear strength of the soil to the shear stress required for equilibrium, where shear strength of the soil can be determined by equation (1). Accordingly, the safety factor $F_{s}$ of a homogeneous infinite unsaturated soil slope is expressed as

$$
\begin{aligned}
F_{s} & =\frac{\tau_{f}}{\tau_{m}}=\frac{c_{t}^{\prime}+\left(\sigma-u_{a}\right) \tan \varphi_{t}^{\prime}+\left(u_{a}-u_{w}\right) \tan \varphi_{t}^{b}}{\tau_{m}}, \\
\sigma & =W \cos ^{2} \alpha=\gamma(H-y) \cos ^{2} \alpha, \\
\tau_{m} & =W \sin \alpha \cos \alpha=\gamma(H-y) \sin \alpha \cos \alpha,
\end{aligned}
$$

where $\alpha=$ slope angle and $y=$ distance from the sliding surface to the water table.

In light of the definition of safety factor in equation (2), theoretical formulations of the safety factor $F_{\mathrm{s}}$ for a homogeneous infinite unsaturated soil slope under hydrostatic and nonhydrostatic conditions are presented, respectively.

3.2.1. Hydrostatic Condition. Regarding the linear suction profile under a hydrostatic condition, the surface matric suction $\left(u_{a}-u_{w}\right)_{0}$ is $\gamma_{w} H \cos ^{2} \alpha$, and matric suction at the depth of $(H-y)$ is written as

$$
\left(u_{a}-u_{w}\right)=\gamma_{w} y \cos ^{2} \alpha
$$

where $\gamma_{w}=$ unit weight of water.

Substituting equation (3) into equation (2), the safety factor $F_{s}$ under a linear suction profile is obtained as 


$$
F_{s}=\frac{\tan \varphi_{t}^{\prime}}{\tan \alpha}+\frac{c_{t}^{\prime}}{\gamma(H-y) \sin \alpha \cos \alpha}+\frac{\gamma_{w} y \tan \varphi_{t}^{b}}{\gamma(H-y) \tan \alpha} .
$$

3.2.2. Nonhydrostatic Condition. For three cases of suction profiles under a nonhydrostatic condition in Figure 2, theoretical formulations of safety factor are identical to equation (4) under the hydrostatic condition where the sliding surface is below the infiltration depth $Z$ due to the fact that $(H-y)>Z$. The safety factor $F_{s}$ of cases I, II, and III under the nonhydrostatic condition is just required to address for $(H-y) \leq Z$, that is, the sliding surface is above the infiltration depth $Z$.

(1) Case I

Matric suction at the depth of $(H-y)$ for case I is written as

$$
\left(u_{a}-u_{w}\right)=\gamma_{w}(H-Z)\left(\frac{H-y}{Z}\right) \cos ^{2} \alpha .
$$

When equation (5) is substituted into equation (2), the safety factor $F_{s}$ of case I is formulated as

$$
F_{s}=\frac{\tan \varphi_{t}^{\prime}}{\tan \alpha}+\frac{c_{t}^{\prime}}{\gamma(H-y) \sin \alpha \cos \alpha}+\frac{\gamma_{w}(H-Z) \tan \varphi_{t}^{b}}{\gamma Z \tan \alpha}
$$

\section{(2) Case II}

Matric suction at the depth of $(H-y)$ is zero for case II, and the safety factor $F_{s}$ of case II is introduced from equation (2) as

$$
F_{s}=\frac{\tan \varphi_{t}^{\prime}}{\tan \alpha}+\frac{c_{t}^{\prime}}{\gamma(H-y) \sin \alpha \cos \alpha} .
$$

(3) Case III

Since the positive pore-water pressure $u_{w}$ at the infiltration depth $Z$ is $\gamma_{w} Z \cos ^{2} \alpha$ for case III, matric suction at the depth of $(H-y)$ is written as

$$
\left(u_{a}-u_{w}\right)=-\gamma_{w}(H-y) \cos ^{2} \alpha .
$$

Substituting equation (8) into equation (2), the safety factor $F_{s}$ of case III is derived as

$F_{s}=\frac{\tan \varphi_{t}^{\prime}}{\tan \alpha}+\frac{c_{t}^{\prime}}{\gamma z(H-y) \sin \alpha \cos \alpha}-\frac{\gamma_{w} \tan \varphi_{t}^{b}}{\gamma \tan \alpha}$.

Equations (6), (7), and (9) are theoretical formulations of safety factor for homogeneous infinite unsaturated soil slopes under a nonhydrostatic condition with $(H-y) \leq Z$, whereas the formulation with $(H-y)>Z$ is identical to equation (4) under the hydrostatic condition. Besides, equations (6), (7), and (9) all consist of three terms. The first two terms are same, and the second term is related to distance $y$ from the sliding surface to the water table. The third term caused by matric suction is different: case I is dependent on the infiltration depth $Z$, and case II is zero, yet case III is a constant. For saturated soils with null matric suction, the first two terms of equations (4), (6), (7), and (9) are only reserved.

3.3. Comparability Analysis. For a linear suction profile under the hydrostatic condition, the safety factor of equation (4) for an unsaturated soil slope takes into consideration the intermediate principal stress effect (i.e., $0 \leq b \leq 1$ ). It can degenerate into several existing formulations of safety factor and has broadly theoretical significance. When $b=0$, equation (4) is reduced to that obeying the MC failure criterion [16]. When $b=1$, equation (4) is based on the twinshear stress failure criterion. Furthermore, a series of new formulations for safety factor including the intermediate principal stress effect are obtained from equation (4) when $0<b<1$.

For three cases of suction profiles under the nonhydrostatic condition, the safety factor of equations (6), (7), and (9) considers comprehensive effects of the intermediate principal stress (i.e., $0 \leq b \leq 1$ ) and the infiltration depth $Z$. When the infiltration depth $Z$ approaches 0 (i.e., $Z \longrightarrow 0$ ), equations (6), (7), and (9) all become as equation (4). It means that equation (4) is a special one of equations (6), (7), and (9). The conventional safety factor using the MC failure criterion is achieved from equations (6), (7), and (9) when $b=0$, which was firstly presented by Rahardjo et al. [13] and then given by Lee et al. [4] and Zhang et al. [1]. Meanwhile, a series of new formulations for the safety factor incorporating the intermediate principal stress effect are generated with $0<b<1$, which can be better applied to practical engineering.

As a result, the proposed safety factor for a homogeneous infinite unsaturated soil slope expressed as equations (4), (6), (7), and (9) has good comparability, which can not only revert to many existing formulations but also introduce more additional new ones considering the intermediate principal stress effect and four different profiles of matric suction.

\section{Verifications of the Proposed Formulation}

The rationality of the proposed formulation of safety factor for homogeneous infinite unsaturated soil slopes is verified in comparison with the results of the extended shear strength method [16] and the finite element method [4].

4.1. A Comparison with the Result of the Extended Shear Strength Method [16]. Zhang et al. [16] dealt with the same problem of this study using the extended shear strength method, and matric suction was assumed to have a linear profile with depth under the hydrostatic condition. The MC failure criterion was employed by Zhang et al. [16] not considering the intermediate principal stress effect, which corresponds to equation (1) of this study with $b=0$. Figure 3 shows a comparison between the results from Zhang et al. [16] and equation (4) of this study with $b=0, c^{\prime}=10 \mathrm{kPa}$, 


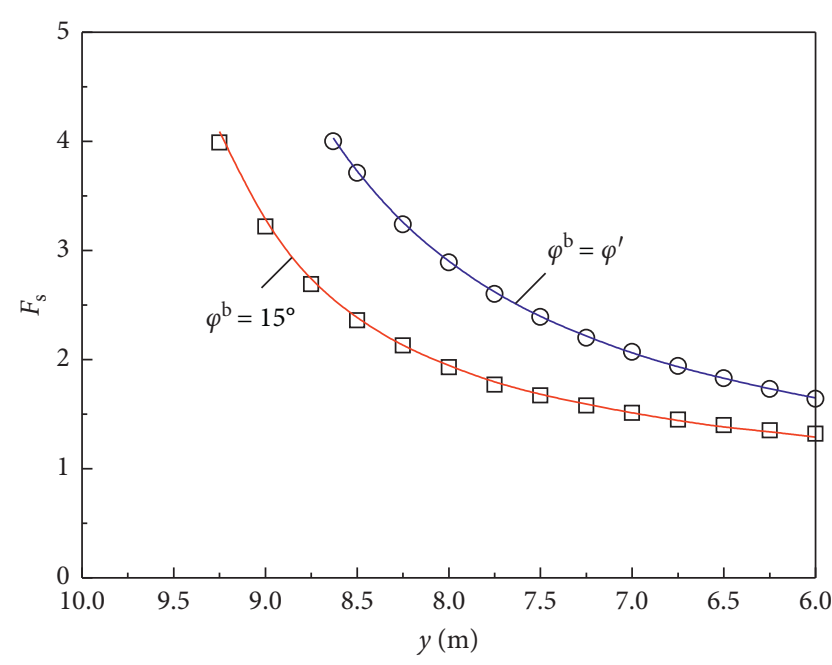

- Extended shear strength method

— This study with equation. (4)

口 Extended shear strength method

— This study with equation. (4)

Figure 3: Comparisons with the extended shear strength method.

$\varphi^{\prime}=34^{\circ}, \gamma=20 \mathrm{kN} / \mathrm{m}^{3}, \alpha=40^{\circ}$, and $H=10 \mathrm{~m}$. Two typical values of the suction angle $\varphi^{b}$ (i.e., $\varphi^{b}=15^{\circ}$, and $\varphi^{\prime}$ ) are analyzed.

Note that the abscissa $y$ of Figure 3 is the distance from the sliding surface to the water table, and thus the depth of the sliding surface is $(H-y)=10-y$. Accordingly, the abscissa $y$ increasing to the left is taken as positive to depict the increase to the depth of the sliding surface. For illustration, the abscissa $y$ of Figure 3 decreases from $9.25 \mathrm{~m}\left(\varphi^{b}=15^{\circ}\right)$ and $8.63 \mathrm{~m}\left(\varphi^{b}=\varphi^{\prime}\right)$ to $6 \mathrm{~m}$, and then the depth of the sliding surface is increased from $0.75 \mathrm{~m}$ to $1.37 \mathrm{~m}$ to $4 \mathrm{~m}$, respectively. The abscissa $y$ of Figure 4 has the same meaning as that of Figure 3.

It can be seen from Figure 3 that equation (4) of this study is well consistent with the result of the extended shear strength method [16] for $\varphi^{b}=15^{\circ}$. This is because the relative error of $1.4 \%$ is a maximum value at $y=9.25 \mathrm{~m}$, and the mean relative error is $0.9 \%$.

Moreover, a better agreement between these two approaches is observed for that of $\varphi^{b}=\varphi^{\prime}=34^{\circ}$ since the mean relative error is only $0.3 \%$. Therefore, the correctness of equation (4) under a linear suction profile is demonstrated. In addition, Figure 3 suggests that the suction angle $\varphi^{b}$ has a dominant influence on the safety factor of unsaturated soil slopes.

\subsection{A Comparison with the Result of the Finite Element} Method [4]. Lee et al. [4] developed a new finite element model to evaluate slope instability triggered by rainfalls. The safety factor of unsaturated soil slopes at two sites was discussed. Table 1 shows the parameters of numerical calculations, where site (1) is fine-grained unsaturated soils and site (2) is coarse-grained unsaturated soils. As described in Figure 4, the numerical result of Lee et al. [4] is compared with equations (4), (6), and (7) of this study with $b=0$ (i.e., the MC failure criterion) under $H=10 \mathrm{~m}, Z=5 \mathrm{~m}$, and $\varphi^{b}=15^{\circ}$. The abscissa $y$ of Figure 4 decreases from $9 \mathrm{~m}$ to 0 , and the sliding surface depth of $(H-y)=10-y$ is then increased from $1 \mathrm{~m}$ to $10 \mathrm{~m}$.

As illustrated in Figure 4(a), this study with equations (4) and (6) agrees well with the numerical result of Lee et al. [4] at site (1). The maximum relative error of $6.1 \%$ occurs at $y=8 \mathrm{~m}$, and the mean relative error is $2.9 \%$, which validate the effectiveness of equations (4) and (6) under the suction profile of case I in this study.

Figure 4(b) indicates that equations (4) and (7) of this study are consistent favorably with that of the finite element method [4] at site (2). The maximum relative error is $7.6 \%$ at $y=4.6 \mathrm{~m}$, and the mean relative error is $3.1 \%$. Thus, the rationality of equations (4) and (7) under the suction profile of case II is verified. Note that a jump of the safety factor appears at $y=5 \mathrm{~m}$ in Figure 4(b). It is because matric suction becomes zero at the sliding surface overlapping with the infiltration depth $Z$ (i.e., $Z=5 \mathrm{~m}$ ) under the suction profile of case II, and the safety factor increases again with the increase of the distance $y$ for $y>5 \mathrm{~m}$.

\section{Parametric Studies}

Parametric studies are conducted to investigate the effects of the intermediate principal stress, the infiltration depth, the slope angle, and effective strength parameters on the safety factor of unsaturated soil slopes through equations (4), (6), (7), and (9) accompanying with four different suction profiles proposed in this study. Influences of each parameter under different suction profiles are compared. Parameters of a homogeneous infinite unsaturated soil slope are as follows: $\alpha=21^{\circ}, \gamma=18.2 \mathrm{kN} / \mathrm{m}^{3}, c^{\prime}=6.5 \mathrm{kPa}, \varphi^{\prime}=30^{\circ}$, and $\varphi^{b}=15^{\circ}$; $H=10 \mathrm{~m}, Z=5 \mathrm{~m}$, and $y=6 \mathrm{~m}$, which signifies that the sliding surface is situated $4 \mathrm{~m}$ below the slope surface corresponding to $(H-y)<Z$.

5.1. Intermediate Principal Stress. The effect of intermediate principal stress on the strength of unsaturated soils is represented by the unified strength theory parameter $b$, and the intermediate principal stress effect is higher with the increase of parameter $b$. Figure 5 displays the variation of the safety factor $F_{\mathrm{s}}$ versus the parameter $b$ under four profiles of matric suction.

From Figure 5, the intermediate principal stress is found to have an important impact on the safety factor of an unsaturated soil slope, and $F_{s}$ increases monotonically with increasing the $b$ value. The lowest $F_{s}$ corresponds with $b=0$ (i.e., the MC failure criterion) not considering the intermediate principal stress effect. It is because that strength potentialities of unsaturated soils are not fully brought. When $b$ varies from 0 to $1, F_{s}$ is increased by $24.3 \%, 23.7 \%$, $20.9 \%$, and $15.8 \%$ for linear suction, for case I, case II, and case III, respectively. It is implied that the intermediate principal stress effect is the most obvious under the linear suction profile.

In addition, the difference of the safety factor for four suction profiles is remarkable. $F_{s}$ is the highest for the linear 


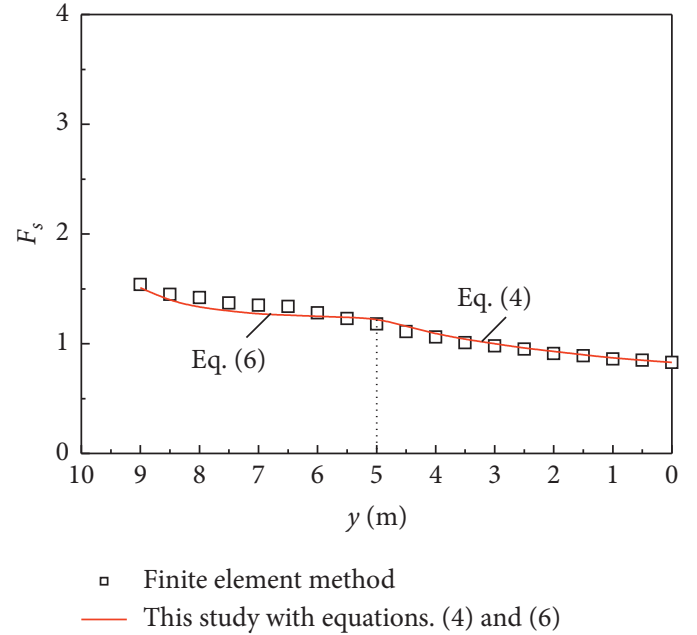

(a)

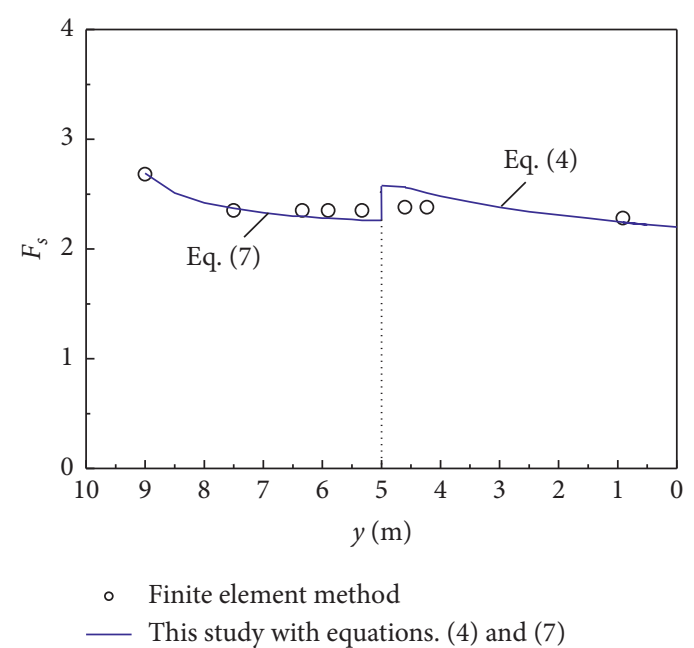

(b)

Figure 4: Comparisons with the finite element method. (a) Site (1). (b) Site (2).

TABle 1: Parameters of two unsaturated soil slopes.

\begin{tabular}{lcc}
\hline Parameters & Site (1) & Site (2) \\
\hline Slope angle $\alpha\left(^{\circ}\right)$ & 30 & 21 \\
Soil unit weight $\gamma\left(\mathrm{kN} / \mathrm{m}^{3}\right)$ & 17.24 & 18.05 \\
Effective cohesion $c^{\prime}(\mathrm{kPa})$ & 2.6 & 3.3 \\
Effective internal friction angle $\varphi^{\prime}\left(^{\circ}\right)$ & 24.6 & 39.5 \\
\hline
\end{tabular}

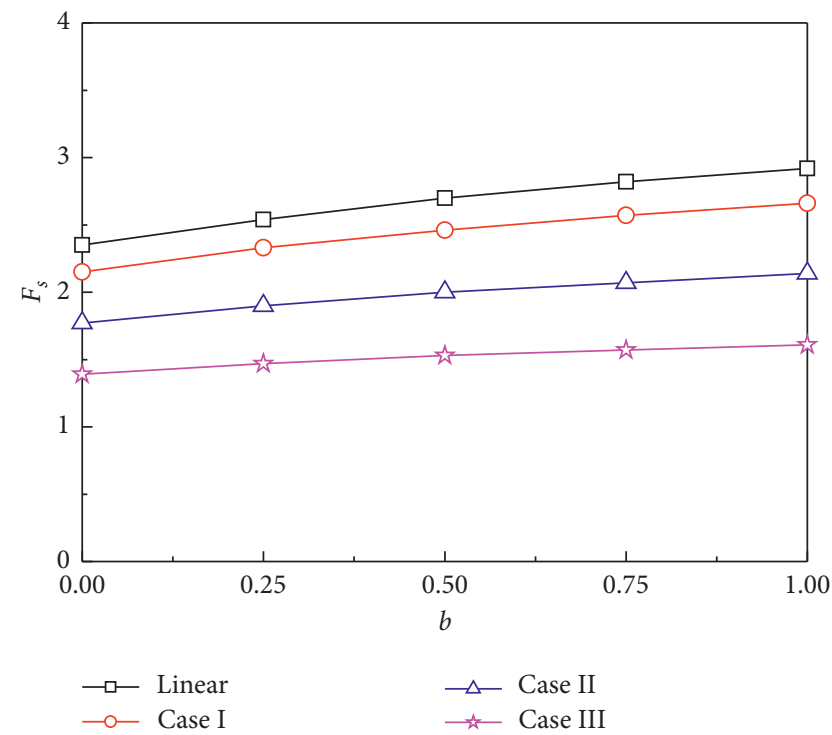

FIGURE 5: Effect of intermediate principal stress.

suction profile, whereas $F_{s}$ is the lowest for case III. As a result, suction profiles of unsaturated soils should be monitored in situ for a long time to better analyze slope stability.

5.2. Infiltration Depth. The infiltration depth affects the safety factor of unsaturated soil slopes with respect to three suction profiles of cases I, II, and III under a nonhydrostatic condition. Figure 6 depicts the relationship between the safety factor $F_{s}$ of three suction profiles and the infiltration depth $Z$ with $b=0.5$.

Figure 6 shows that the variation of the safety factor $F_{s}$ versus the infiltration depth $Z$ is divided into two stages. For $Z<4 \mathrm{~m}$ as stage I, i.e., $(H-y)=10-6=4 \mathrm{~m}>Z$, the values of matric suction at $y=6 \mathrm{~m}$ are identical under three suction profiles of cases I, II, and III. The corresponding $F_{\mathrm{s}}$ has thus the same value as a constant of 2.7 calculated by equation (4), which is regardless of the infiltration depth. For $Z>4 \mathrm{~m}$ as stage II, i.e., $(H-y)=4 \mathrm{~m}<Z, F_{\mathrm{s}}$ decreases nonlinearly with $Z$ for case I, while $F_{\mathrm{s}}$ for cases II and III is two smaller constants. It provides the significance of selecting a rational and practical suction profile. Specifically, when $Z=4 \mathrm{~m}$, i.e., $(H-y)=4 \mathrm{~m}=Z$, matric suction at $y=6 \mathrm{~m}$ for cases II and III becomes zero, and the corresponding $F_{\mathrm{s}}$ is suddenly decreased by $25.9 \%$ and $43.3 \%$, respectively. Moreover, case III has the largest reduction in the safety factor.

5.3. Slope Angle. The slope angle is largely used to characterize the infinite slope geometry [35]. Figure 7 describes the relationship between the safety factor $F_{\mathrm{s}}$ and the slope angle $\alpha$ under four suction profiles and $b=0.5$.

It is seen from Figure 7 that $F_{\mathrm{s}}$ decreases nonlinearly with the increase of $\alpha$. When $\alpha$ increases from $20^{\circ}$ to $40^{\circ}, F_{\mathrm{s}}$ is decreased by $54.2 \%, 54.1 \%, 53.3 \%$, and $52.2 \%$ for linear suction, for case I, case II, and case III, respectively. Therefore, the inclination of infinite slopes should be consciously reduced to enhance its intrinsic stability.

5.4. Effective Strength Parameters. The effective cohesion $c^{\prime}$ and the effective internal friction angle $\varphi^{\prime}$ are two primary strength parameters of unsaturated soils in a completely saturated state. Effect of effective strength parameters on the safety factor $F_{s}$ of unsaturated soil slopes is presented in Figure 8 under four suction profiles and $b=0.5$. 


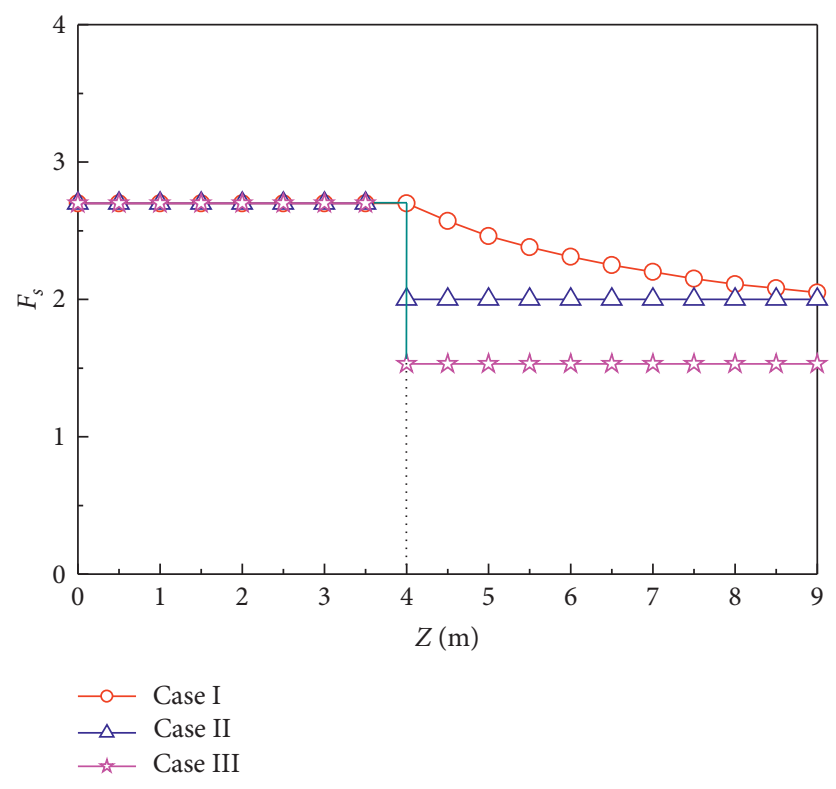

FigURE 6: Effect of the infiltration depth.

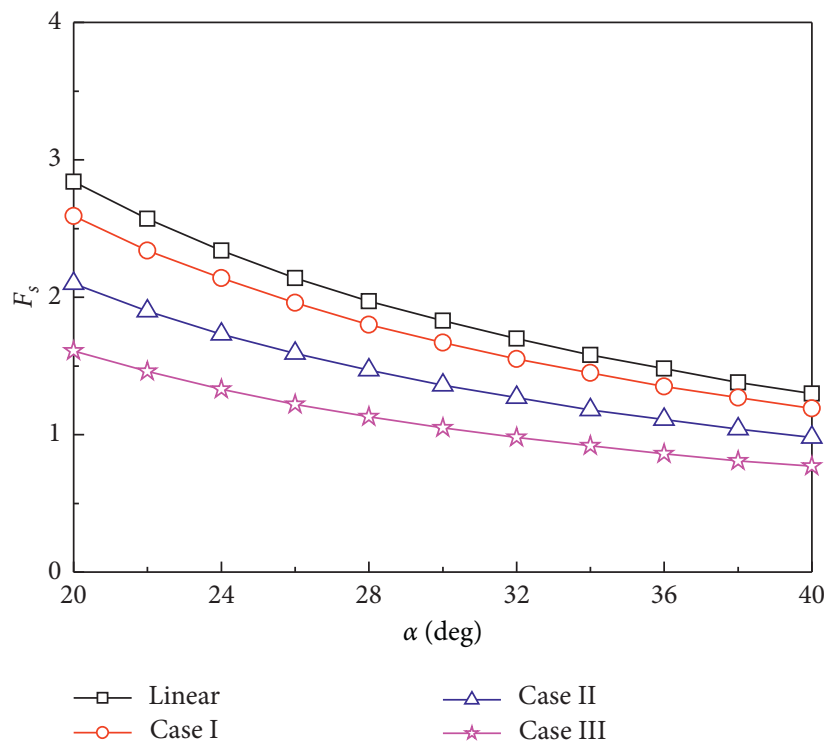

FIgURE 7: Effect of the slope angle.

Figure 8 illustrates that $F_{\mathrm{s}}$ increases linearly as effective strength parameters of unsaturated soils increase, and the slope stability is clearly improved under four suction profiles. Nonetheless, this effect is more evident for the effective cohesion $c^{\prime}$ than the effective internal friction angle $\varphi^{\prime}$.

\section{Discussion}

The unified strength theory parameter $b$ in the proposed theoretical formulation of safety factor for unsaturated soil slopes should be firstly determined in practical applications. It implies that basic mechanical properties (e.g., uniaxial compressive strength, uniaxial tensile strength, and pure shear strength) or true triaxial strength values of unsaturated soils sampled from landslide sites are required through conducting relevant laboratory tests. Moreover, the specific suction profile of landslide sites is field surveyed to identify whether it belongs to one case of the four suction profiles in consideration or other one.

In this study, the presented theoretical formulation of safety factor for unsaturated soil slopes is merely adaptable to steady unsaturated infiltration conditions which restrict direct applications of the obtained analytical framework to actual rainfall-induced landslides. From the practical point of view, a rainfall-induced landslide is predicted for temporal and spatial failure occurrences under rainfall events rather than those in the steady state [36]. It is inappropriate to adopt the steady-state groundwater flow concept to 


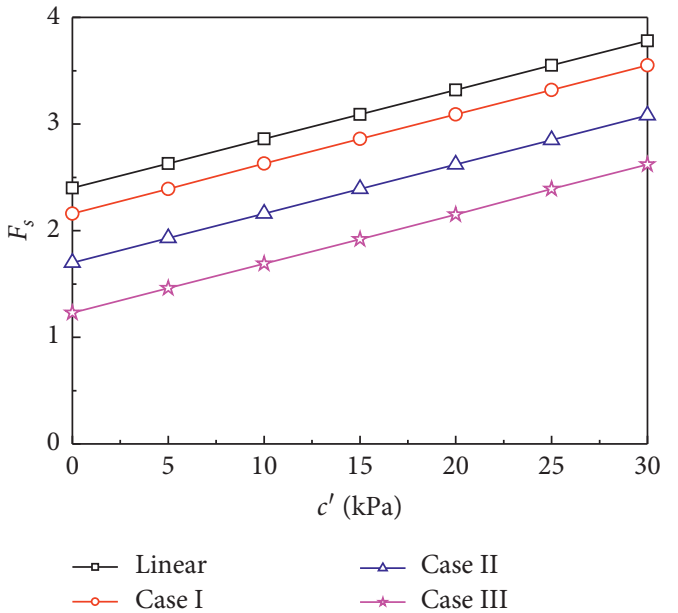

(a)

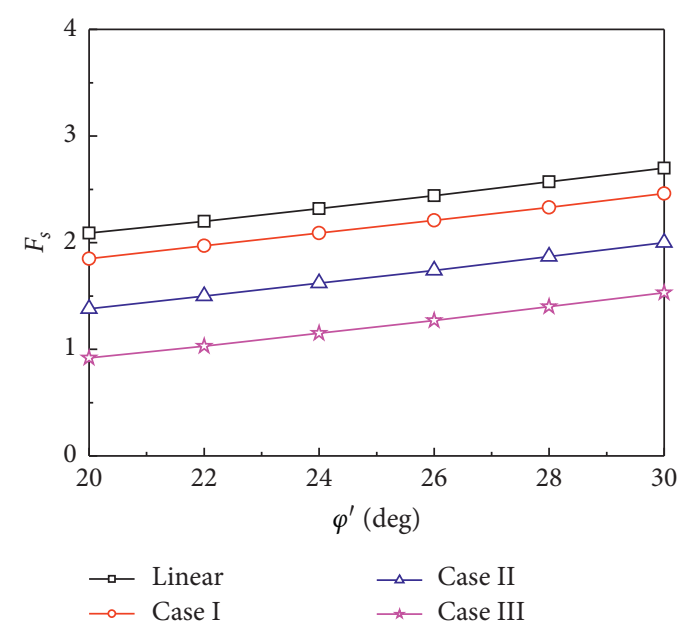

(b)

Figure 8: Effect of effective strength parameters. (a) Effective cohesion. (b) Effective internal friction angle.

directly evaluate triggering mechanisms of rainfall-induced landslides under transient unsaturated seepage conditions [37]. The potential failure mechanism, timing, and depth of unsaturated slope instability in practice can be scrutinized using a series of coupled hydromechanical numerical modeling for transient infiltrations and multidimensional calculations along with rainfall data.

Primary factors of slope stability analysis commonly encountered will be focused on in the future work, such as the heterogeneity in soil properties, rainfall intensity and duration, heterogeneous hydraulic properties, and hydraulic boundary conditions. Meanwhile, it is paid more attention to the choice of various soil-water characteristic curve models in analyzing unsaturated soil slope stability during the transient process. Inclusions of variable soil parameters in a probabilistic manner and stability enhancement due to vegetation are two important steps for realistic estimations of shallow rainfall-induced landslides [38].

\section{Conclusions}

(1) The proposed theoretical formulation of safety factor for homogeneous infinite unsaturated soil slopes can reasonably account for the intermediate principal stress effect under four different profiles of matric suction. The traditional safety factors for saturated and unsaturated soils based on the MC failure criterion are special cases of the proposed formulation, and a series of new formulations for the safety factor are provided. Good agreements are achieved between theoretical predictions of the proposed formulation and reported results of the extended shear strength method and the finite element method. Accordingly, the proposed formulation of safety factor for unsaturated soil slopes has good comparability and broad applicability.

(2) The intermediate principal stress is found to have a significant effect on the safety factor of unsaturated soil slopes, and the safety factor of the MC failure criterion is remarkably small. For a linear suction profile within the four suction profiles investigated, the safety factor is the highest and the intermediate principal stress effect is the most conspicuous. The infiltration depth has a decisive impact on the safety factor of unsaturated soil slopes for the suction profile of cases I, II, and III, and the variation of the safety factor versus the infiltration depth is classified as two stages. In addition, the effect of the slope angle on the safety factor cannot be neglected, and the effective cohesion has a more obvious effect than the effective internal friction angle.

\section{Data Availability}

The data used to support the findings of this study are available from the corresponding author upon request.

\section{Conflicts of Interest}

The authors declare that there are no conflicts of interest regarding the publication of this paper.

\section{Acknowledgments}

The financial supports provided by the Opening Fund of State Key Laboratory of Geohazard Prevention and Geoenvironment Protection (grant no. SKLGP2020K022) and the Fundamental Research Funds for the Central Universities, CHD (grant nos. 300102289720, 300102280108, and 300102411401) are gratefully acknowledged.

\section{References}

[1] L. L. Zhang, J. Zhang, L. M. Zhang, and W. H. Tang, "Stability analysis of rainfall-induced slope failure: a review," Proceedings of the Institution of Civil Engineers-Geotechnical Engineering, vol. 164, no. 5, pp. 299-316, 2011.

[2] L. Z. Wu, R. Q. Huang, and X. Li, Hydro-Mechanical Analysis of Rainfall-Induced Landslides, Springer, Beijing, China, 2020. 
[3] B. D. Collins and D. Znidarcic, "Stability analyses of rainfall induced landslides," Journal of Geotechnical and Geoenvironmental Engineering, vol. 130, no. 4, pp. 362-372, 2004.

[4] L. M. Lee, N. Gofar, and H. Rahardjo, "A simple model for preliminary evaluation of rainfall-induced slope instability," Engineering Geology, vol. 108, no. 3-4, pp. 272-285, 2009.

[5] H. Ling and H. I. Ling, "Centrifuge model simulations of rainfall-induced slope instability," Journal of Geotechnical and Geoenvironmental Engineering, vol. 138, no. 9, pp. 1151-1157, 2012.

[6] M. Pirone, R. Papa, M. V. Nicotera, and G. Urciuoli, "In situ monitoring of the groundwater field in an unsaturated pyroclastic slope for slope stability evaluation," Landslides, vol. 12, no. 2, pp. 259-276, 2015.

[7] J. J. Lizárraga and G. Buscarnera, "Safety factors to detect flowslides and slips in unsaturated shallow slopes," Géotechnique, vol. 68, no. 5, pp. 442-450, 2017.

[8] A. Chueasamat, T. Hori, H. Saito, T. Sato, and Y. Kohgo, "Experimental tests of slope failure due to rainfalls using $1 \mathrm{~g}$ physical slope models," Soils and Foundations, vol. 58, no. 2, pp. 290-305, 2018.

[9] S. Zhang, X. C. Zhang, X. J. Pei et al., "Model test study on the hydrological mechanisms and early warning thresholds for loess fill slope failure induced by rainfall," Engineering Geology, vol. 258, Article ID 105135, 2019.

[10] A. Johari and A. Talebi, "Stochastic analysis of rainfall-induced slope instability and steady-state seepage flow using random finite-element method," International Journal of Geomechanics, vol. 19, no. 8, Article ID 4019085, 2019.

[11] X. Wei, W. Fan, Y. Cao et al., "Integrated experiments on field monitoring and hydro-mechanical modeling for determination of a triggering threshold of rainfall-induced shallow landslides. a case study in Ren river catchment, China," Bulletin of Engineering Geology and the Environment, vol. 79, no. 1, pp. 513-532, 2020.

[12] K. S. Kim, M. I. Kim, M. S. Lee, and E. S. Hwang, "Regression equations for estimating landslide-triggering factors using soil characteristics," Applied Sciences, vol. 10, no. 10, Article ID 3560, 2020.

[13] H. Rahardjo, T. T. Lim, M. F. Chang, and D. G. Fredlund, "Shear-strength characteristics of a residual soil," Canadian Geotechnical Journal, vol. 32, no. 1, pp. 60-77, 1995.

[14] N. Lu and J. Godt, "Infinite slope stability under steady unsaturated seepage conditions," Water Resources Research, vol. 44, no. 11, Article ID w11404, 2008.

[15] Q. B. Travis, S. L. Houston, F. A. M. Marinho, and M. Schmeeckle, "Unsaturated infinite slope stability considering surface flux conditions," Journal of Geotechnical and Geoenvironmental Engineering, vol. 136, no. 7, pp. 963-974, 2010.

[16] L. L. Zhang, D. G. Fredlund, M. D. Fredlund, and G. W. Wilson, "Modeling the unsaturated soil zone in slope stability analysis," Canadian Geotechnical Journal, vol. 51, no. 12, pp. 1384-1398, 2014.

[17] T. Vo and A. R. Russell, "Stability charts for curvilinear slopes in unsaturated soils," Soils and Foundations, vol. 57, no. 4, pp. 543-556, 2017.

[18] W. G. Huang, E. C. Leong, and H. Rahardjo, "Upper-bound limit analysis of unsaturated soil slopes under rainfall," Journal of Geotechnical and Geoenvironmental Engineering, vol. 144, no. 9, Article ID 4018066, 2018.

[19] L. Z. Wu, L. M. Zhang, Y. Zhou et al., "Theoretical analysis and model test for rainfall-induced shallow landslides in the red-bed area of Sichuan," Bulletin of Engineering Geology and the Environment, vol. 77, no. 4, pp. 1343-1353, 2018.

[20] H. Matsuoka, D. A. Sun, A. Kogane, N. Fukuzawa, and W. Ichihara, "Stress-strain behaviour of unsaturated soil in true triaxial tests," Canadian Geotechnical Journal, vol. 39, no. 3, pp. 608-619, 2002.

[21] L. R. Hoyos, D. D. Pérez-Ruiz, and A. J. Puppala, "Refined true triaxial apparatus for testing unsaturated soils under suction-controlled stress paths," International Journal of Geomechanics, vol. 12, no. 3, pp. 281-291, 2012.

[22] C. G. Zhang, X. D. Chen, W. Fan, and J. H. Zhao, "A new unified failure criterion for unsaturated soils," Environmental Earth Sciences, vol. 74, no. 4, pp. 3345-3356, 2015.

[23] S. J. Shao, Q. Wang, and A. Z. Luo, "True triaxial apparatus with rigid-flexible-flexible boundary and remolded loess testing," Journal of Testing and Evaluation, vol. 45, no. 3, pp. 808-817, 2017.

[24] F. Zheng, S. J. Shao, J. Wang, and S. Shao, "Experimental study on the mechanical behaviour of natural loess based on suction-controlled true triaxial tests," KSCE Journal of Civil Engineering, vol. 24, no. 8, pp. 2304-2321, 2020.

[25] C. G. Zhang, J. H. Zhao, Q. H. Zhang, and F. Xu, "Unified solutions for unsaturated soil shear strength and active earth pressure," in Proceedings of the GeoShanghai 2010-Experimental and Applied Modeling of Unsaturated Soils (GSP 202), pp. 218-224, Shanghai, China, June 2010.

[26] C. G. Zhang, Y. S. Hu, and J. H. Zhao, "Unified solution of shear strength for unsaturated soil under plane strain condition and its application," Chinese Journal of Geotechnical Engineering, vol. 33, no. 1, pp. 32-37, 2011, in Chinese.

[27] M. H. Yu, Unified Strength Theory and its Applications, Springer-Verlag, Berlin, Germany, 2004.

[28] D. G. Fredlund, N. R. Morgenstern, and R. A. Widger, "The shear strength of unsaturated soils," Canadian Geotechnical Journal, vol. 15, no. 3, pp. 313-321, 1978.

[29] C. G. Zhang, X. D. Chen, and W. Fan, "Critical embedment depth of a rigid retaining wall against overturning in unsaturated soils considering intermediate principal stress and strength nonlinearity," Journal of Central South University, vol. 23, no. 4, pp. 944-954, 2016.

[30] Q. Yan, J. H. Zhao, C. G. Zhang, and J. T. Wang, "Ultimate bearing capacity of strip foundations in unsaturated soils considering the intermediate principal stress effect," Advances in Civil Engineering, vol. 2020, Article ID 8854552, , 2020.

[31] C. G. Zhang, J. H. Zhao, and Y. Dai, "Investigation on filling height of embankment on unsaturated soft ground with stiff crust," Chinese Journal of Theoretical and Applied Mechanics, vol. 48, no. 2, pp. 482-494, 2016, in Chinese.

[32] C. Yao and X. L. Yang, "Limit analysis of unsaturated soil slope stability considering intermediate principal stress and strength nonlinearity," Geotechnical and Geological Engineering, vol. 35, no. 5, pp. 2053-2063, 2017.

[33] T. T. Lim, H. Rahardjo, M. F. Chang, and D. G. Fredlund, "Effect of rainfall on matric suctions in a residual soil slope," Canadian Geotechnical Journal, vol. 33, no. 4, pp. 618-628, 1996.

[34] D. G. Milledge, D. V. Griffiths, S. N. Lane, and J. Warburton, "Limits on the validity of infinite length assumptions for modelling shallow landslides," Earth Surface Processes and Landforms, vol. 37, no. 11, pp. 1158-1166, 2012.

[35] D. Chatterjee and A. Murali Krishna, "Effect of slope angle on the stability of a slope under rainfall infiltration," Indian Geotechnical Journal, vol. 49, no. 6, pp. 708-717, 2019. 
[36] K. Pham, D. Kim, H.-J. Choi, I.-M. Lee, and H. Choi, "A numerical framework for infinite slope stability analysis under transient unsaturated seepage conditions," Engineering $\mathrm{Ge}$ ology, vol. 243, pp. 36-49, 2018.

[37] Y. Matsushi, T. Hattanji, and Y. Matsukura, "Mechanisms of shallow landslides on soil-mantled hillslopes with permeable and impermeable bedrocks in the Boso Peninsula, Japan," Geomorphology, vol. 76, no. 1-2, pp. 92-108, 2006.

[38] J. W. Godt, B. Şener-Kaya, N. Lu, and R. L. Baum, "Stability of infinite slopes under transient partially saturated seepage conditions," Water Resources Research, vol. 48, no. 5, Article ID w05505, 2012. 